\title{
Development and Characterization of Knit Fabric from Jute Fibre
}

\author{
Dr. Nazmina Chowdhury ${ }^{1}$, Nayer Sultana ${ }^{1 *}$, Md. Asib Iqbal ${ }^{1}$, Tahnin Binte Kamal $^{2}$, Md. Ariful Islam $^{1}$ \\ ${ }^{1}$ Pilot Plant and Processing Division, Bangladesh Jute Research Institute, Dhaka 1207, Bangladesh \\ ${ }^{2}$ Mechanical Processing Division, Bangladesh Jute Research Institute, Dhaka 1207, Bangladesh
}

\begin{abstract}
DOI: $\underline{10.36348 / \text { sjet.2020.v05i10.006 }}$
| Received: 28.09.2020 | Accepted: 12.10.2020 | Published: 21.10.2020
\end{abstract}

*Corresponding author: Nayer Sultana

\section{Abstract}

Jute is the golden fibre of Bangladesh, we hold a large share in the international jute market. Traditionally jute fiber is used to produce yarn and woven fabric. The properties of jute fiber indicates that it can be successfully used to produce knitted fabrics. We can use jute instead of synthetic fibre.This work compares the major quality parameters of knit fabric - weight, fabric density, dimensional stability, spirality, bursting strength, abrasion resistance and pilling, thermal conductivity and wash fastness are tested and assessed the performance of jute in replace of synthetic or cotton for apparel concern. All results are better and acceptable as compare to ISO norms.

Keywords: Knit fabric, jute fibre, comfort properties.

Copyright ( $) 2020$ The Author(s): This is an open-access article distributed under the terms of the Creative Commons Attribution 4.0 International License (CC BY-NC 4.0) which permits unrestricted use, distribution, and reproduction in any medium for non-commercial use provided the original author and source are credited.

\section{INTRODUCTION}

Knitting is considered to be the second most frequently used fabric construction method, here needles are used for interlocking loops of yarns to produce fabrics. The knitting method was first developed in the Middle East around the $5^{\text {th }}$ century CE, and spread to other parts of the world. Knit fabrics are popular worldwide due to their excellent mechanical and comfort properties. The last few years have witnessed growing interest in knitted fabrics due to their simple production techniques, low cost, high levels range. Knitted fabrics are known to possess excellent comfort properties as they not only allow for stretching and ease of movement, but they also have good handling characteristics for the body. They also possess high extensibility under low load, allowing comfortable fit on any part pulled. Furthermore they are also light weight and flexible [1].

Knits are comfortable fabrics, as they adapt to body movement. The loop structure contributes to elasticity beyond what is capable of the yarns or fibers alone. A knit fabric is prone to snagging, and has a higher potential shrinkage than a woven fabric. The loop structure also provides many cells to trap air, and thus provides good insulation in still air. Knits are not typically very wind- or water-repellent [2]. of clothing comfort and wide product
The Knitting process involves the inter looping or intra looping of yarn in a series of connected loops by means of needles. There are two major types of knitting: weft knitting and warp knitting. In the more common weft knitting, the wales are perpendicular to the course of the yarn. In warp knitting, the wales and courses run roughly parallel. In weft knitting, the entire fabric may be produced from a single yarn, by adding stitches to each wale in turn, moving across the fabric as in a raster scan. By contrast, in warp knitting, one yarn is required for every wale. Since a typical piece of knitted fabric may have hundreds of wales, warp knitting is typically done by machine, whereas weft knitting is done by both hand and machine [3]. Cut (or gauge) and stitch density are used to represent the closeness of the intermeshing loops. Cut or gauge indicates the number of knitting needles per unit length along the crosswise or lengthwise direction. The greater the number, the closer together the loops are to each other. Stitch density is the number of stitches per unit area, obtained by multiplying the number of courses per inch $(25 \mathrm{~mm})$ by the number of wales per inch $(25 \mathrm{~mm})$ [4]. Single jersey is weft knitted fabric made with a single set of needles. These fabrics are warm, stretchy, flexible and comfortable to wear.

Traditionally synthetic fibers, wool and cotton are mostly used for knit fabric production whereas jute is a readily available natural fiber that can be used to replace these costly fibres. Lycra or elastane is a synthetic fiber known for its exceptional elasticity. It 
is a polyether-polyurea copolymer that was invented in 1958 by chemist Joseph Shivers at DuPont's Benger Laboratory in Waynesboro, Virginia [5]. Jute is a long, soft, shiny vegetable fiber that can be spun into coarse, strong threads. It is produced primarily from plants in the genus Corchorus, which was once classified with the family Tiliaceae, and more recently with Malvaceae. The primary source of the fiber is Corchorusolitorius, but it is considered inferior to Corchoruscapsularis [6]. The major constituents of jute are cellulosic materials making it an excellent candidate for knit fabric production. This study was aimed to investigate the comfort and mechanical properties of jute knitted fabrics as a replacement of the more expensive knit fabrics.

\section{MATERIALS AND METHODS Materials}

Jute cotton blended yarn, (Ring and Rotor) 18' and lycra yarn (20 \& 40 D) was collected from local sources.

\section{Methods}

Knitted Fabric Production (Grey) Rib structure was made by Flat-bed machine using full needle, cam mechanical device. Local raw materials Yarn 18' and lycra 40D were used to develop knitted fabrics using different relaxation techniques. The knitted fabrics were characterized by testing its geometrical properties like wales per inch, course per inch after each state of relaxation.

\section{DYEING AND FINISHING Heat Setting}

The lycra fabrics - jute lycra $(98 \% \& 2 \%)$ and jute cotton lycra $(58 \%, 40 \% \& 2 \%)$ are stretched to the required width and set permanently by passing it through the curing chamber at $180-185^{\circ} \mathrm{C}$ for 30 seconds to 1 minute in a stenter machine.

\section{Bleaching}

The fabrics were joined lengthwise by sewing and treated in jigger machine. The fabric was then treated in a water solution containing $2 \%$ detergent/wetting agent, $2 \%$ anti creasing agent and $1 \%$ sequestering agent. The samples were treated with 20:1 liquor to sample ratio at $45^{\circ} \mathrm{c}$ for $20 \mathrm{mins}$. Then natural impurities were removed using $3 \%$ caustic soda $(\mathrm{NaOH}), 10 \%$ hydrogen peroxide $\left(\mathrm{H}_{2} \mathrm{O}_{2}\right)$ and $1 \%$ peroxide stabilizer at $95^{\circ} \mathrm{C}$ for one hour. Then the sample fabrics are given a fresh wash with $1 \%$ peroxide killer/remover at $50^{\circ} \mathrm{C}$ for ten minutes and treated with $1 \%$ acetic acid at $40^{\circ} \mathrm{C}$ for neutralization at $\mathrm{pH}$ of 6.5 for five minutes.

\section{Dyeing}

The bleached fabrics were dyed in the jigger machine with a mixture of dyes (Remazol Red RR $0.90 \%$, Novacron Blue FN-R 0.6\% and Indofix Black $\mathrm{B} 0.01 \%$ based on sample weight). In addition Salt 20 gpl, Soda ash 5gpl, Levelling agent 2gpl, Anti creasing agent 1gpl, Sequestering agent 1gpl and Wetting/penetrating agent $1 \mathrm{gpl}$ were used based on the amount of water used for dyeing. The $\mathrm{M}$ : $\mathrm{L}$ ratio was maintained at $1: 15$ and temperature at $65^{\circ} \mathrm{C}$ for $50 / 60$ minutes. Then the samples were washed off at $80^{\circ} \mathrm{C}$ for $10 / 12$ minutes with $1.5 \mathrm{gpl}$ soaping agent (detergent), drained and rinsed with fresh water for ten minutes to remove unfixed dyes and chemicals from the fabric. Then again washed off at $50^{\circ} \mathrm{C}$ for $10 / 12$ minutes with water only and at last treated with acetic acid with $1 \mathrm{gpl}$ for neutralization at $40^{\circ} \mathrm{C}$ for $5 / 7$ minutes. The samples were then squeezed in a hydro-extractor to release the excess water and make the fabric ready for dryer.

\section{Finishing}

The dyed samples were treated with softener $30 \mathrm{gpl}$ and acetic acid 1 gpl to maintain neutral $\mathrm{pH}$. The fabric was then passed through stenter machine at 120$150^{\circ} \mathrm{C}$.

\section{Compacting}

In order to improve the hand-feel and to stabilize the fabric it was compacted by steaming at 100 $-110^{\circ} \mathrm{C}$ for $15 / 20$ seconds. The fabric was subjected to compressive shrinkage in the length and width direction by mechanical processing.

\section{TREATED FABRIC CHARACTERIZATION Bursting Strength Test}

Bursting strength is a measure of breaking force in which the knit fabric is stressed in all directions at the same time. Here an increasing pressure is vertically applied on the fabric. The pressure in the fluid increases at such a rate that the specimen bursts within $20 \pm 3 \mathrm{sec}$. The strength is measured at break point in lbs/sq. inch. The sample fabrics are conditioned under standard testing atmosphere i.e.65 $\pm 2 \% \mathrm{RH}$ and $27 \pm 2^{\circ} \mathrm{C}$ for $24 \mathrm{hrs}$ before conducting the test.

\section{Abrasion Test \\ The sample fabrics were conditioned at first under standard testing atmosphere. Random circular specimens were taken from each sample fabric. The specimens were then stretched over the face of the circular holders and rubbed against the flat abrasive surface placed on the lower plates. The machine was run until hole(s) appeared. A total weight of $395.35 \mathrm{gm}$ was applied to the specimens with a motion that was continually changing direction and the counter counted the number of revolutions/strokes required for end point and recorded to the table. The worst cloth was used as standard abradant.}

\section{Pilling Test}

Pilling is formed on fabric surface during wear and washing by the entanglement of loose fibers. The property of the pilling formed on the surface and/or can be retained on the surface was assessed by standard pilling images of the treated fabrics. 


\section{Shrinkage Test}

Shrinkage of the treated fabrics were measured by the mechanical shrinkage method under standard atmosphere. The treated specimens $(50 \times 50 \mathrm{~cm})$ were washed in water at $40^{\circ} \mathrm{C}$ for 30 minutes. The changes in the length and width direction were measured after drying and the shrinkage was calculated according to the following equation:

Shrinkage $=[($ the length before wash - the length after wash) $\div$ the length before wash] x $100 \%$

\section{Spirality}

Spirality is the dimensional distortion of the fabric after washing according to seam length and is calculated according to the following equation:

Spirality $=($ side seam actual length before wash/side seam displacement length after wash) $\mathrm{x} 100 \%$

\section{Wash Fastness Test}

Wash fastness is the ability of fabrics to retain the dyes used to color them. Specimens from each of the dyed sample fabrics was tested with the adjacent cotton fabric under standard conditions. The change in color of the sample and also color staining on the adjacent fabric were assessed and the rating is expressed in fastness numbers. A $10 \times 4 \mathrm{~cm}$ swatch of the colored fabric is taken and is sandwiched between two adjacent cotton fabrics and stitched. The sample and the adjacent fabric are washed together with soap $5 \mathrm{gpl}$ and soda $2 \mathrm{gpl}$ solution at $50^{\circ} \mathrm{C}$ for 30 minutes. The liquor material ratio was 50:1. After soaping treatment, the specimen was removed and rinsed twice in cold water and then in running cold water under a tap. The samples were squeezed it and air dried at a temperature not exceeding $60^{\circ} \mathrm{C}$. At last, the change in color and staining was evaluated with the help of grey scales.

\section{RESULTS AND DISCUSSION}

The devloped knitted fabric was characterized to evaluate the comfort and mechanical properties and compare them with traditional knit fabrics. The fabrics were tested for their mechanical properties, comfort and handling properties. The test results showed that the weight of the fabric was heavily dependent on the loop lengths. Variations in the loop length can be used to design light and airy fabrics according to requirement. In both plain single jersey and 1/1 Lycra Rib fabrics variations in the loop length resulted in variations in the fabrics GSM, WPI, CPI, shrinkage and spirality. The stich density was also affected by the loop length as it is the product of WPI and CPI.

Table-1: Different properties of knitted fabrics

\begin{tabular}{|l|l|l|l|l|l|l|}
\hline Fabric Type & Loop length mm & GSM & WPI & CPI & Shrinkage \% & Spirality \% \\
\hline Plain Single Jersey & 3.2 & 180 & 22 & 20 & 4.5 & 4.0 \\
\cline { 2 - 7 } & 3.3 & 178 & 21 & 21 & 4.2 & 3.5 \\
\cline { 2 - 6 } & 3.4 & 165 & 22 & 20 & 4.1 & 4.5 \\
\hline \multirow{4}{*}{ 1/1 Lycra Rib } & 4.2 & 190 & 23 & 21 & 3.9 & 3.0 \\
\cline { 2 - 6 } & 4.5 & 195 & 24 & 22 & 3.8 & 2.6 \\
\cline { 2 - 6 } & 4.7 & 200 & 23 & 21 & 3.6 & 2.9 \\
\hline
\end{tabular}

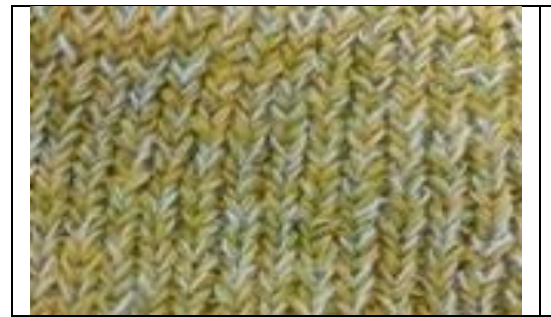

Rib (1 X 1)

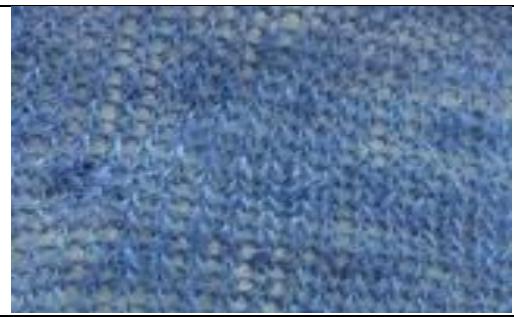

Single jersey dyed jute knitted fabric

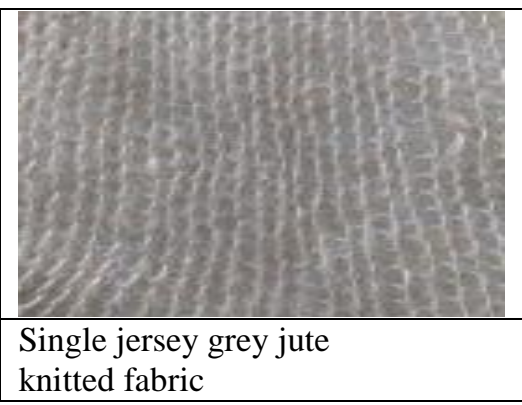

knitted fabric

\section{Figure: Photographs of developed knitted fabrics}

Table-2: Fabric Density: WPI \& CPI

\begin{tabular}{|l|l|l|l|l|}
\hline \multirow{2}{*}{ Name of Sample Fabric } & Yarn Count & Wale Density WPI & $\begin{array}{l}\text { Course Density } \\
\text { CPI }\end{array}$ \\
\cline { 2 - 3 } & Jute cotton blended (Ne) & Lycra Deniar & & 21 \\
\hline Single Jersey & 20 & 20 & 21 & 21 \\
\hline Rib 1/1 & 18 & 40 & 23 & 23 \\
\hline
\end{tabular}

Table-3: Stich density

\begin{tabular}{|l|l|l|l|}
\hline Name of Sample Fabric & WPI & CPI & Stitch Density (S) = WPI x CPI \\
\hline Single Jersey Plain & 21 & 19 & $21 \times 19=399$ \\
\hline Rib 1/1 & 23 & 21 & $23 \times 21=483$ \\
\hline
\end{tabular}


Nazmina Chowdhury et al; Saudi J Eng Technol, October, 2020; 5(10): 392-396

The test results of fabric characterization shows that the shrinkage and spirality of the developed fabrics are better compared to international standard $( \pm$
$5 \%$ for single jersey and $\pm 6 \%$ for rib). Moreover the rib fabric produced better results than the single jersey in terms of shrinkage and spirality.

Table-4: Dimensional Stability (Shrinkage) and Bursting Strength Test Results

\begin{tabular}{|l|l|l|l|l|l|l|}
\hline $\begin{array}{l}\text { Name of Sample } \\
\text { Fabric }\end{array}$ & $\begin{array}{l}\text { Loop Length } \\
\mathrm{mm}\end{array}$ & GSM & \multicolumn{2}{|l|}{ Shrinkage \% } & Spirality\% & $\begin{array}{l}\text { Bursting } \\
\text { (lbs/in }^{\mathbf{2}} \text { ) }\end{array}$ \\
\hline Single Jersey Plain & 3.3 & & Length & Width & & Strength \\
\hline Rib & 4.5 & 175 & -4.2 & -2.1 & 3.5 & 1223.36 \\
\hline
\end{tabular}

The loop length used to develop the knitted fabric has an inverse relationship with the GSM and the bursting strength of the developed fabric. This was expected as longer loops give rise to less dense fabric causing lower GSM. This lower density also contributes to the reduction of bursting strength.

Table 5: Test Results of GSM against Loop length

\begin{tabular}{|c|c|c|c|c|}
\hline \multirow[t]{2}{*}{ Name of Sample Fabric } & \multicolumn{2}{|l|}{ Yarn Count } & \multirow[t]{2}{*}{ Loop Length mm } & \multirow[t]{2}{*}{ Weight GSM } \\
\hline & Jute Cotton Blended Ne & LycraD & & \\
\hline \multirow[t]{6}{*}{ Single Jersey Plain } & \multirow[t]{6}{*}{18} & \multirow[t]{6}{*}{20} & 3.4 & 180 \\
\hline & & & 3.3 & 175 \\
\hline & & & 3.2 & 172 \\
\hline & & & 3.1 & 172 \\
\hline & & & 3.2 & 174 \\
\hline & & & 3.1 & 171 \\
\hline \multirow[t]{6}{*}{ Rib 1/1 } & \multirow[t]{6}{*}{18} & \multirow[t]{6}{*}{40} & 4.7 & 210 \\
\hline & & & 4.5 & 203 \\
\hline & & & 4.2 & 200 \\
\hline & & & 4.3 & 201 \\
\hline & & & 4.3 & 202 \\
\hline & & & 4.4 & 203 \\
\hline
\end{tabular}

The test results for stitch density also reveals a slight variation in single jersey knit fabric construction and rib knit fabric construction. The rib construction has considerably higher stitch density that single jersey construction.

Table-6: Calculation of Stich Density as WPI \& CPI

\begin{tabular}{|l|l|l|l|}
\hline Name of Sample Fabric & WPI & CPI & Stitch Density $($ S) = WPI x CPI \\
\hline \multirow{4}{*}{ Single Jersey Plain } & 21 & 20 & $21 \times 20=420$ \\
\cline { 2 - 4 } & 22 & 21 & $21 \times 22=462$ \\
\cline { 2 - 4 } & 21 & 23 & $21 \times 23=483$ \\
\hline \multirow{3}{*}{ Rib 1/1 } & 23 & 21 & $23 \times 21=483$ \\
\cline { 2 - 4 } & 21 & 23 & $21 \times 23=483$ \\
\cline { 2 - 4 } & 22 & 22 & $22 \times 22=484$ \\
\hline
\end{tabular}

Table-7: Shrinkage \&Spirality Test Result

\begin{tabular}{|l|l|l|l|l|l|}
\hline Name of Sample Fabric & \multirow{2}{*}{ Loop Length mm } & \multirow{2}{*}{ GSM } & \multicolumn{2}{|l|}{ Shrinkage \% } & \multirow{2}{*}{ Spirality \% } \\
\cline { 3 - 6 } & & & Length & Width & \\
\hline \multirow{3}{*}{ Single Jersey Plain } & 3.3 & 175 & -4.2 & -2.1 & 3.5 \\
\cline { 2 - 5 } & 3.2 & 172 & -4.1 & -2.5 & 3.4 \\
\cline { 2 - 5 } & 3.1 & 172 & -4.1 & -2.7 & 3.4 \\
\hline \multirow{3}{*}{ Rib 1/1 } & 4.5 & 203 & -3.8 & -1.9 & 2.7 \\
\cline { 2 - 5 } & 4.7 & 210 & -3.9 & -2.0 & 2.9 \\
\cline { 2 - 5 } & 4.3 & 201 & -3.8 & -2.2 & 2.7 \\
\hline
\end{tabular}

The abrasion resistance of the developed fabric was higher than the desired number of movements (acceptable standard movements 3500). The pilling characteristics was also very good as compared to standard norms. The wash fastness (change and staining) of dyed samples is good as grey scale assessment. 
Nazmina Chowdhury et al; Saudi J Eng Technol, October, 2020; 5(10): 392-396

Table-8: Test results of Bursting Strength, Abrasion Resistance\& Pilling

\begin{tabular}{|l|l|l|l|}
\hline Name of Sample fabric & Bursting Strength $\left(\mathbf{l b s} / \mathbf{i n}^{2}\right)$ & Abrasion Resistance no. of cycle & Pilling pills/area \\
\hline \multirow{4}{*}{ Single Jersey Plain } & 1223.36 & 5233 & 4 \\
\cline { 2 - 4 } & 1220.39 & 5220 & 4 \\
\cline { 2 - 4 } & 1221.00 & 5215 & 4 \\
\hline \multirow{4}{*}{ Rib 1/1 } & 4838.51 & 6838 & 4 \\
\cline { 2 - 4 } & 4835.00 & 6833 & 4 \\
\cline { 2 - 4 } & 4833.20 & 6815 & 4 \\
\hline
\end{tabular}

\section{CONCLUSION}

In this work, the major quality parameters of knit fabric - weight, fabric density, dimensional stability, spirality, bursting strength, abrasion resistance and pilling, thermal conductivity and wash fastness etc. were tested and the suitability of jute for replacing synthetic or cotton fibre in knit fabric was assessed. The mechanical and comfort parameters of jute knit fabrics were found to be better than traditional knit fabrics and were acceptable as compared to ISO norms. Jute can be used as a replacement for synthetic and cotton fibre.

\section{REFERENCE}

1. Felczak, M., De Mey, G., Więcek, B., \& Michalak, M. (2015). Lateral and Perpendicular Thermal Conductivity Measurement on Textile
Double Layers. Fibres \& Textiles in Eastern Europe.

2. Blair, K. B. (2007). Materials and design for sports apparel Materials in Sports Equipment, 2.

3. David, J. S. (1989). Knitting Technology a comprehensive handbook and practical guide Third edition, 11-12.

4. Li, Y., \& Dai, D. X. (Eds.). (2006). Biomechanical engineering of textiles and clothing. Woodhead Publishing.

5. "Knitting Basics". Alamac American Knits LLC. 2004. Archived from the original on 2007-02-27. Retrieved 2006-12-27.

6. U.S. Patent 3,023,192, "Segmented copolyetherester elastomers" filed May 29, 1958, issued Feb 27, 1962.

7. "Plants for a Future", Pfaf.org, retrieved 21 May 2015. 